\title{
FACES AND FINGERS: AUTHENTICATION
}

\author{
Nathan Reitinger*
}

\begin{abstract}
$\underline{\text { Abstract }}$
One of the most shocking outcomes of the pre-digital law versus post-digital world is the currently unconfirmed holding that although law enforcement may not compel the production of a password to unlock a mobile device, a finger, and likely a face, is fair game. You may be forced to "look" at your iPhone or "press" your finger against its fingerprint reader, but recitation of your password is off the table. Both logically and legally this result is quizzical. Merging these divergent outcomes, which both end in the same result - accessis the aim of this Essay, using as fodder a technical understanding of "authentication," the organic statute behind device unlock. Because the sine qua non of authentication is identification and verification, unlocking a device necessarily imparts a truth telling: an expression of exclusivity, ownership, and control. These qualities are inherently testimonial; therefore, compelled device unlock based on a fingerprint or facial scan should be deemed to infringe upon the Fifth Amendment's protection against self-incrimination.
\end{abstract}

* Ph.D. Candidate, University of Maryland, Department of Computer Science. M.S., Computer Science Security Track, Columbia University '19. J.D., Michigan State University College of Law' 15.

Copyright (C) 2020 Journal of High Technology Law and Nathan Reitinger. All Rights Reserved. ISSN 1536-7983. 


\section{Introduction}

Imagine you have the desire to protect digital information stored on a mobile device. Would you feel comfortable using a mobile device with an unlock feature automatically triggered by an infrared scan of your face? Stated concretely, if you own an iPhone with FaceID, should you anticipate being compelled to look at your phone, thus permitting access to those unsavory Google search queries ${ }^{1}$ or poorly thought-through selfies $?^{2}$ Indeed, the only mechanism standing between the law and your secrets is your phone's "lock" screeninstantly, automatically, and, once set up, unstoppably "unlocked" with a simple glance.

At face value, the answer to this question turns on the Fifth Amendment's ability to protect physical features. Historically, this has played out through a game of analogy: is the compulsion more like surrendering a physical key or a mental key? ${ }^{3}$ If the key involves no state-of-mind component (i.e., a physical feature), then the compulsion is likely non-testimonial and does not violate the Fifth Amendment. ${ }^{4}$ However, if the key does involve some quantum of mental state, then the compulsion is likely testimonial, protected by the Fifth Amendment. ${ }^{5}$

\footnotetext{
${ }^{1}$ Perhaps it was one of these searches: "Where to buy the world's largest baking dish? How to properly tie a woman to a rotating life-size barbeque spit? How to chloroform a girl?" See Rahul Bhagnari, When Does Your Google Search Become a Crime, ACLU (May 13, 2015), archived at https://perma.cc/MD39-6RS9 (querying Google to feed a fantasy may not be enough to be considered a smoking gun, but the evidence does have a tendency to make its way into court).

${ }_{2}^{2}$ See Associated Press, Teen Who Took Selfie with Murdered Friend Learns Fate (May 15, 2017), archived at https://perma.cc/PFA9-SDWA (discussing a case where an eighteen-year-old shot his friend and then took a selfie with the dying teen). This selfie later took on the term "death selfie." Id.

${ }^{3}$ See Kendall Howell, The Fifth Amendment, Decryption and Biometric Passcodes, LAWFARE (Nov. 27, 2017), archived at https://perma.cc/GH9S-CQMA (expressing the increasing hurdle that law enforcement are now regularly facing when it comes to extracting data from a person's device). Further, this issue is no longer just about obtaining a passcode, but possibly a biometric verification. Id.

${ }^{4}$ See id. (noting that courts agreed with the decision that the "Fifth Amendment does not protect against the production of physical features or acts"); see also infra Part II.

${ }^{5}$ See id. (finding that so long as the communication "explicitly or implicitly, relate[s] a factual assertion or disclose[s] information," then it is considered testimonial); see also infra Part II.
} 
In this vein, courts consider passwords to be testimonial, meaning it is unlawful to compel the production of a special phrase, but fingerprints non-testimonial, making it lawful to compel the placement of a finger on a mobile device. ${ }^{6}$ Although this conclusion is not consistent across the board, a trend is identifiable. ${ }^{7}$ And in terms of a face, which easily places itself in the physical camp, the game of analogy would likely return a non-testimonial, just-tell-me-where-tolook answer. ${ }^{8}$

${ }^{6}$ See Commonwealth v. Baust, No. CR14-1439, 2014 WL 10355635, at *4 (Va. Cir. Ct. Oct. 28, 2014) ("In this case, the Defendant cannot be compelled to produce his passcode to access his smartphone but he can be compelled to produce his fingerprint to do the same.").

${ }^{7}$ See e.g., In re Single-Family Home \& Attached Garage, No. 17M85, 2017 WL 4563870 , at $* 2$ (N.D. Ill. Feb. 21, 2017).

The government does not seek authority to force the individuals to enter passcodes into the devices if necessary to unlock them, apparently recognizing that this would violate the Fifth Amendment. It is only if the Apple device has been configured in advance to unlock in response to the individual's unique fingerprint (the biometric passcode), that the government asserts the Fifth Amendment does not apply. In its view, law enforcement would be compelling a mere physical act rather than a communicative act.

Id. Nevertheless, this court disagreed with the government, concluding that both acts are implicit testimony, which result in the individual unlocking the device. Id.

${ }^{8}$ See Pratik Parikh, iPhone X: Unlocking the Self Incrimination Clause of the Fifth Amendment, 45 RuTGERS COMP. \& TECH. L.J. 58, 87-88 (2019) (finding that passwords are protected, but fingers and faces are likely not); Erin M. Sales, The "Biometric Revolution": An Erosion of the Fifth Amendment Privilege to Be Free from Self-Incrimination, 69 U. MIAMI. L. REV. 193, 222 (2014) (explaining that" $[\mathrm{p}] \mathrm{recedent}$ indicates that people will simply have less constitutional protection in testimonial evidence that may be contained in their mobile consumer devices") (emphasis added); Laurent Sacharoff, Unlocking the Fifth Amendment: Passwords and Encrypted Devices, 87 FordHAM L. REV. 203, 241 (2018) (proposing that the government only be able to compel a suspect to hand over information that they already know is on the device); Efren Lemus, When Fingerprints Are Key: Reinstating Privacy to the Privilege Against Self-Incrimination in Light of Fingerprint Encryption in Smartphones, 70 SMU L. REV. 533, 554 (2017) (finding that current law would place finger and face based authentication in the physical and therefore permissible camp - though disagreeing with this conclusion for privacybased reasons). But see Madeline Leamon, Unlocking the Right Against SelfIncrimination: A Predictive Analysis of 21st Century Fifth Amendment Jurisprudence, 64 WAYNE L. REV. 583, 584-85 (2019) (concluding that the testimonial qualities of biometric locks warrant protection under the Fifth 
Missing from the debate, however, is a technical understanding of the "why" behind device unlock. What are the properties driving the mechanics of device unlock, and why are those properties necessary for the mechanism to be considered "good enough" for public use? The simple answer here is authentication-the means of identifying and verifying users. ${ }^{9}$

Following a brief legal overview of compelled device unlock, this short Essay unpacks the technical underpinnings of authentication in the context of FaceID. FaceID is Apple's newest unlock mechanism which, in simple terms, uses a face as a key. ${ }^{10}$ This understanding is then applied to the constitutional inquiry, concluding that the primitives of authentication necessarily impart a substance in and of itself. Authentication, in this sense, is a form of truth telling-an expression of exclusivity, ownership, and control. Compelling the use of a finger or face to unlock a phone should not be deemed different than compelling the recitation of a password. Whether finger, face, or

Amendment); Kara Goldman, Biometric Passwords and the Privilege Against SelfIncrimination, 33 CARDOZO ARTS \& ENT. L.J. 211, 226-27, 234-35 (2015) (imploring that fingerprints when used to unlock a phone should be considered testimonial because it is taking on the job of a traditional numeric or alphabetic password).

9 The term "authentication" takes on a different definition in the computer science literature as opposed to the legal literature, which often uses the term authentication when considering evidence. Compare Authentication, TECHTERMS (July 13, 2018), archived at https://perma.cc/WZ7W-4WWQ (defining authentication in computer science literature as "the process of verifying the identity of a person or device"), with Authentication Law and Legal Definition, USLEGAL (Jan. 11, 2020), archived at https://perma.cc/U96T-65XW (defining authentication in legal literature as a "testimony by a proper party that a document is what it is purported to be and that the party attesting to it is qualified to do so"). Authentication here may be thought of as "you are who you say you are." See infra Part III Section B.

${ }^{10}$ See Face ID Security, APPLE (Nov. 2017), archived at https://perma.cc/B5XWJVK2 (describing how iPhone FaceID works).

With a simple glance, Face ID securely unlocks iPhone X. It provides intuitive and secure authentication enabled by the TrueDepth camera system, which uses advanced technologies to accurately map the geometry of your face. Face ID confirms attention by detecting the direction of your gaze, then uses neural networks for matching and anti-spoofing so you can unlock your phone with a glance. Face ID automatically adapts to changes in your appearance, and carefully safeguards the privacy and security of your biometric data.

Id. 
phrase, all are a form of truth telling, and thus should be deemed protected under the Fifth Amendment.

\section{Testimonial Communication: Truth Telling}

"No person ... shall be compelled in any criminal case to be a witness against himself." 11 Although three independent inquiries spring from this one constitutional sentence, ${ }^{12}$ the jurisprudential fireworks have mostly been reserved for the last, a testimonial communication. Further, the Supreme Court has graced us with a fair share of its own communication in discussing the acts that constitute the meaning of "testimonial."

In one of the first cases to draw a hard line, Holt v. United States,${ }^{13}$ the Court found the act of putting on a blouse to see if it would fit the defendant to be non-testimonial. ${ }^{14}$ The Court disagreed with defendant's argument that the action was unconstitutionally compelled, or, as the defendant argued, an "extravagant extension of the Fifth Amendment." 15 In support of its decision, the Court stated that prohibiting compulsion to extract communications from a defendant is distinct from the use of a defendant's body as evidence. ${ }^{16}$ If the use of a defendant's body as evidence was prohibited, then it

${ }^{11}$ U.S. CONST. amend. V.

12 An (1) incriminating (2) compulsion of (3) testimonial communication. See United States v. Doe, 670 F.3d 1335, 1341 (11th Cir. 2012); see also Doe v. United States, 487 U.S. 201, 212 (1988) (discussing how the historical underlying policies regarding the self-incrimination privilege were to prevent a suspect from being compelled into producing information that would incriminate them).

13218 U.S. 245 (1910).

${ }^{14}$ See id. at 252-53.

A question arose as to whether a blouse belonged to the prisoner. A witness testified that the prisoner put it on and it fitted him. It is objected that he did this under the same duress that made his statements inadmissible, and that it should be excluded for the same reasons. But the prohibition of compelling a man in a criminal court to be witness against himself is a prohibition of the use of physical or moral compulsion to extort communications from him, not an exclusion of his body as evidence when it may be material. The objection in principle would forbid a jury to look

Id. at a prisoner and compare his features with a photograph in proof.

${ }^{15}$ See id. at 252.

${ }^{16}$ See id. 
would in essence "forbid a jury to look at a prisoner and compare his features with a photograph." 17 From there, the rest was easy: providing a blood sample, ${ }^{18}$ voice or hand-writing exemplar, ${ }^{19}$ or required presence in a police line-up ${ }^{20}$ were all deemed nontestimonial.

The identifiable theme, beyond physicality, was that neutral actions (i.e., those having no bent toward substance in and of themselves) are not protected by the Fifth Amendment. As stated in Hubbell v. United States, ${ }^{21}$ although the contents of a document may be privileged, the "act of production' may implicitly communicate statements of fact." 22 This is to say, physical features merely exist, and requiring them to be plainly displayed — regardless of the feature's identifying ${ }^{23}$ characteristics - does not give rise to constitutionally protected substance or facts.

More recently, however, less-clear cases have attempted to blur this line. One of the most interesting, In re Grand Jury Subpoena to Sebastian Boucher, decided in 2007 ("Boucher I") and revised in 2009 ("Boucher II"), ${ }^{24}$ involved access to a computer containing illegal content. Although the computer had been consensually accessed by a security guard unveiling illicit material, on later inspection, encrypted files put a hard-stop to the investigation. ${ }^{25}$ Law enforcement could not practically or theoretically ${ }^{26}$ view these files without a passcode,

${ }^{17}$ See id. at 253.

${ }^{18}$ See Schmerber v. California, 384 U.S. 757, 761 (1966).

19 See Gilbert v. California, 388 U.S. 263, 266-67 (1967).

${ }^{20}$ See United States v. Wade, 388 U.S. 218, 222-23 (1967).

${ }^{21} 167$ F.3d 552 (D.C. Cir. 1999), aff'd, 530 U.S. 27 (2000).

${ }^{22}$ See United States v. Hubbell, 530 U.S. 27, 37 (2000) (stating that the "act of production" is the act of producing documents in response to a subpoena).

${ }^{23}$ See United States v. Hubbell, 167 F.3d 552, 574-75 (D.C. Cir. 1999), aff'd, 530 U.S. 27 (2000) (citing Schmerber v. California, 384 U.S. 757, 764 (1966)). Identification in this sense is not the same as using the evidence for a truthtelling effect. While a person's hand or a person's finger communicates - this is my hand or $m y$ finger - the individual proffering the hand is merely being "compelled to make himself available as a source of "real or physical evidence." Id. "For purposes of Fifth Amendment analysis, it is dispositive that the government has no need to rely upon the witness's truthtelling to secure the evidence it seeks." Id.

${ }^{24}$ See In re Grand Jury Subpoena to Sebastien Boucher (Boucher I), No. 2:06-mj-91, 2007 WL 4246473, at *2 (D. Vt. Nov. 29, 2007), rev'd (Boucher II), No. 2:06-mj91, 2009 WL 424718 (D. Vt. Feb. 19, 2009).

${ }^{25}$ See Boucher II, 2009 WL 424718, at *4-6.

${ }^{26}$ Assuming a thirty-character password, the number of guesses it would take to find the password is $591,222,134,364,399,413,463,902,591,994,678,504,204,696,392$, 
which the defendant did not want to divulge. ${ }^{27}$ Although the district court seemed to find favor with the defendant's Fifth Amendment argument, it eventually pivoted, finding that although the files were protected by the Fifth Amendment, the computer had already been inspected, and therefore the "foregone conclusion" applied. ${ }^{28}$

The foregone conclusion has its roots in Fisher $v$. United States,${ }^{29}$ where an accountant attempted to have documents withheld that were already known in existence and location to the government. ${ }^{30}$ The Court ruled in favor with the government, finding that the documents were not being compelled for "truth telling" purposes. Rather, the government already "knew" of the documents' existence and merely needed the metaphorical lock to be released. ${ }^{31}$ Likewise,

694,759,424. See Aloni Cohen \& Sunoo Park, Compelled Decryption and the Fifth Amendment: Exploring the Technical Boundaries, 32 HARV. J. L. \& TECH. 169, 17679 (2018).

An encryption algorithm is a procedure that, given a piece of information (sometimes called a 'plaintext') and a password (sometimes called a 'secret key'), produces an encryption [i.e. an encrypted version of the plaintext] (sometimes called a 'ciphertext'). A decryption algorithm is a procedure that, given an encryption and a password, produces the original piece of information (i.e. the plaintext).

Id. The quoted material refers to symmetric encryption, where a "secret key" is used for both encrypting a piece of plaintext and decrypting a piece of ciphertext. Id. Other forms of encryption exist (e.g., asymmetric encryption), which use two different secret keys for encryption and decryption. Id.; see also Panayotis Vryonis, Explaining Public-Key Cryptography to Non-Geeks: It's Not as Complicated as it Sounds, MEDIUM (Aug. 27, 2013), archived at https://perma.cc/RBU7-FJMX (providing a high-level, easily-digestible overview of asymmetric encryption).

27 See Boucher II, 2009 WL 424718, at *4-6.

${ }^{28}$ See Boucher I, 2007 WL 4246473, at *8-9 (comparing entering a password into a computer with merely asking a person to enter the password into the computer). Unfortunately, this leads to the "forbidden trilemma; incriminate [oneself], lie under oath, or find [oneself] in contempt of court." But see Orin S. Kerr, Compelled Decryption and the Privilege Against Self-Incrimination, 97 TEXAS L. REV. 767 (2019) (discussing the foregone conclusion doctrine, which "limits the Fifth Amendment protection to cases in which the government is trying to use the target's testimony to convict him"). Further, divulging a password implicitly communicates ownership and control - a truth telling warranting protection. See Boucher II, 2009 WL 424718, at *9-10.

29425 U.S. 391 (1976).

${ }^{30}$ See id. at 394-95, 411.

${ }^{31}$ See id. 
the government in Boucher II had enough knowledge of the illegal material's existence (i.e., these files had already been seen) to bypass the Fifth Amendment's privilege and compel production of the courtdeemed mental state (i.e., the password).

Exemplifying the above concerns culminates in Justice Stevens's dissent in Doe v. United States. ${ }^{32}$ Here, the majority found that compelling a defendant to sign a consent decree releasing banking records was not testimonial because it was not an implicit or explicit factual assertion disclosing incriminating information. ${ }^{33}$ It is notable that the Court focused heavily on the language of the consenting instrument. "[T]he form does not acknowledge that an account [exists] or that it is controlled by petitioner. Nor does the form indicate whether documents or any other information relating to petitioner are present at the foreign bank .... The form does not even identify the relevant bank." 34 Again, this comes from the through-line in Fisher-truth telling. The majority argued that the release form permitting disclosure was not used for its "truth telling" effect. In other words, the form was viewed as more of a logistical lock to the substance rather than the substance in and of itself. But it is on this point-a point further exemplified by the properties of authentication ${ }^{35}$ - that Justice Stevens disagreed.

Justice Stevens noted how the defendant's forced signature on the release was necessarily tied to a statement of fact. "The [consent decree] itself may not betray any knowledge petitioner may have about the circumstances of the offenses being investigated by the grand jury, but it nevertheless purports to evidence a reasoned decision by Doe to authorize action by others." 36 Although implied ownership is a somewhat tenuous form of authorization, and not enough for the majority to disallow the compulsion, it is enough-according to

32487 U.S. 201 (1988).

${ }^{33}$ See id. at $208-10$.

${ }^{34} I d$. at 215.

${ }^{35} I d$. at 216.

Nor would his execution of the form admit the authenticity of any records produced by the bank. Not only does the directive express no view on the issue, but because petitioner did not prepare the document, any statement by Doe to the effect that it is authentic would not establish that the records are genuine. Authentication evidence would have to be provided by bank officials.

Id. (internal citation omitted).

${ }^{36} I d$. at 219 (Stevens, J., dissenting). 
Justice Stevens - to warrant a pause. This gave rise to Justice Stevens noting how a defendant may be "forced to surrender a key to a strongbox containing incriminating documents, but [may not be] compelled to reveal the combination to his wall safe-by word or deed." 37

Indeed, Justice Stevens's statement has become the cornerstone of a growing body of case law viewing the testimonialnon-testimonial distinction as hinging on a physical-mental distinction. ${ }^{38}$ We can see this in United States $v$. Kirschner, ${ }^{39}$ where a defendant was permitted to withhold his computer password from the government because it imbued his state of mind. ${ }^{40}$ Further, this is also seen in Commonwealth v. Baust, ${ }^{41}$ where the court found a passcode protected by the law (i.e., a content of the mind), but a fingerprint unprotected by the law (i.e. a mere physical attribute). ${ }^{42}$ The trend continued in State v. Diamond, ${ }^{43}$ where the court held that compelling a defendant to use a finger to unlock a phone "is no more testimonial than furnishing a blood sample, providing handwriting or voice exemplars, standing in a lineup, or wearing particular clothing."44

Additionally, the physical-non-physical distinction is currently the favored approach by law enforcement. For example, in a district court in California, pursuant to a warrant, a defendant was required to "place his face in front of an iPhone X" that was found in his possession during the course of an execution of a warrant. ${ }^{45}$ Similarly, a memorandum with a genesis of the Central District of California argued that using a fingerprint to unlock a device is simply and solely a physical endeavor - something entirely beyond the fingers of the Fifth Amendment. ${ }^{46}$

${ }^{37}$ Id.

${ }^{38}$ See supra note 7 and accompanying text.

39823 F. Supp. 2d 665 (E.D. Mich. 2010).

40 See id. at 668 (compelling a defendant to utter a password is a testimonial communication).

${ }^{41}$ No. CR14-1439, 2014 WL 10355635, at *4 (Va. Cir. Ct. 2014).

${ }^{42}$ See id.

43905 N.W.2d 870 (Minn. 2018).

${ }^{44}$ Id. at 873 .

45 See Affidavit in Support of Search Warrant, No. 2:18-mj-707, II 40 (Sept. 19, 2018), archived at https://perma.cc/NF7F-2Y7J.

46 Memorandum of Points and Authorities (May 9, 2016), archived at https://perma.cc/SZ8E-H76Z (noting how fingerprints are physical in nature). 
Rejecting this trend, however, and understanding the nuance of Justice Steven's statement, is In re Single-Family Home \& Attached Garage. ${ }^{47}$ In this case, the court looked beyond the superficial physical-non-physical inquiry and asked "whether, under the specific facts and circumstances presented, the act [being compelled] implicitly conveys incriminating information unknown to the government." 48 Here, the government "request[ed] that the court authorize law enforcement to press the fingers [of several subjects found] at the Subject Premises to the Touch ID sensor of any Apple brand device[s] found at the Subject Premises." 49 Curtly, law enforcement wanted to conduct a brute-force, guess-and-check method to see which suspects matched which phones, and then search the contents of those phones once unlocked.

Viewing an "unlock" as more of a symbolic act, as found in the Fisher case's dicta, the court was able to see this for what it really is: an expression of ownership - a statement of substance in and of itself. $^{50}$ The court noted how, in today's age, a simple fingerprint can reproduce the entire contents of a device. ${ }^{51}$ At minimum, a fingerprint expresses current possession and control over a device. ${ }^{52}$ True enough, the holding here is limited by this court's statement on the trial-and-error method to be used by the government. ${ }^{53}$ Nonetheless, In re Single-Family Home \& Attached Garage marks an important pushback against a growing trend to demarcate constitutionality based on physical or mental compulsion.

${ }^{47}$ No. 17M85, 2017 WL 4563870 (N.D. Ill. Feb. 21, 2017).

${ }^{48} I d$. at $* 22-23$.

${ }^{49} I d$. at $* 2$.

${ }^{50}$ See id. at *22-23 ("[T]he individual necessarily communicates information to the government when he unlocks the device and thereby produces the contents: that he has accessed the device before (at a minimum to set up the biometric passcode), and currently possesses and controls the device and its contents.”); Fisher, 425 U.S. 391 (1976).

${ }^{51}$ See In re Single-Family Home \& Attached Garage, 2017 WL 4563870, at *5.

${ }^{52}$ See id. (explaining that the person whose finger can open the device implicitly communicates that they control and possess that device).

${ }^{53}$ See id. at *9. Without evidence demonstrating that a specific Apple device belongs to the specific individual who will be forced to unlock it (making the testimonial aspect of the production a foregone conclusion), the compelled act would violate the Fifth Amendment. Id. 


\section{Keys and Locks}

Surprisingly, the Fifth Amendment debate we find ourselves in is driven by technologies that themselves have received scant attention in the conversation. Yet, passwords, pins, fingers, and faces have all been subject to incredible amounts of research in the technical literature. ${ }^{54}$ More importantly, the overarching principle behind all of these technologies - authentication - is given the left-swipe by many courts. Bridging that gap, and in turn offering a more nuanced understanding of the issues, this Essay uses FaceID as a vehicle for digging into the ins and outs of locks - specifically, biometric locks.

\section{A. Biometrics}

The public's familiarity with biometrics is not owed to a new invention, but an old technology that has recently been given a facelift. ${ }^{55}$ The facelift comes from a culmination of two specific advances: (1) neural networks and (2) sensors. ${ }^{56}$ In turn, the ability to "recognize" faces was first introduced at technical conferences, which approached human-level quality and allowed for mass public use.

Using a neural network for facial recognition goes something like this: the neural network takes as input the image of a face and produces as output a prediction of whose face it is. ${ }^{57}$ Under the covers,

${ }^{54}$ See generally William STAllings \& LAWRIE BRown, COMPUTER SECURITY: PRINCIPLES AND PRACTICE (Pearson, 3d ed. 2015) (discussing authentication in terms of security - a backbone consideration in all systems); ABRAHAM Silberschatz, Peter Baer Galvin \& Greg Gagne, Operating Systems CONCEPTS 685-89 (John Wiley \& Sons, Inc., 9th ed. 2013) (examining authentication in terms of an operating system - the means by which computers operate).

${ }^{55}$ See Andrew Bud, Facing the Future: The Impact of Apple FaceID, 2018 BIOMETRIC TECH. TODAY 5, 5 (2018) (setting forth how "[f]ace-matching authentication has been in the market for many years"). Numerous companies have offered some version of face-matching technology over the past 15 years. Id.; see also W. Zhao et al., Face Recognition: A Literature Survey, 35 ACM COMPUTING SURVEYS 399 (2003).

${ }^{56}$ See Bud, supra note 55, at 5; Zhao et al., supra note 55, at 399; Face ID Security, supra note 10, at 3 (discussing at a high level the neural network and TrueDepth sensors involved in FaceID).

${ }^{57}$ See Steven M. Bellovin, Preetam K. Dutta \& Nathan Reitinger, Privacy and Synthetic Datasets, 22 Stan. TeCH. L. Rev. 1, 23-29 (2019) (discussing the 
this involves: (1) creating a mathematical representation of the image; (2) running this representation through a series of pre-set filters, ${ }^{58}$ which highlight features in the image like edges or straight lines (i.e., feature hunting); and (3) using the result of step two's feature hunting to drop the images into labeled buckets. ${ }^{59}$ If the bucket is the same one that the user created when setting up FaceID, then the phone will unlock.

The above summary is what researchers from Facebook and Tel Aviv University demonstrated in 2014, vastly improving the stateof-the-art technology for facial image recognition at the time. ${ }^{60}$ In fact, shortly after their paper came out, Google released their own research relying on a similar technique which demonstrated even better results. ${ }^{61}$ However, the problem with both approaches, in terms of public release at the time, was with in-the-wild recognitions, which suffered from factors like pose, illumination, expressions, and facial changes. ${ }^{62}$ When these factors are present, something else is needed to meet human-level quality classification.

To overcome the difficulties of changing faces and lighting, researchers introduced a series of sensors to give neural networks an additional dimension of feature information. ${ }^{63}$ In part, this is why

processing of using a pre-trained neural network model to recognize hand-drawn digits).

${ }^{5}$ See id. Here we are using a pre-trained model which already knows how to recognize a face. See id. at 29. Training the model to learn this is another subject entirely. Id.

${ }^{59}$ See id.

60 See Yaniv Taigman et al., DeepFace: Closing the Gap to Human-Level Performance in Face Verification, CONF. COMP. VISION \& PATTERN RECOGNITION (2014) (finding, in unconstrained environments, that the machine learning algorithm could perform at accuracy levels of $97.35 \%$ ).

${ }^{61}$ See Florian Schroff, Dmitry Kalenichenko \& James Philbin, FaceNet: A Unified Embeding for Facial Recognition and Clustering, CONF. COMP. VISION \& PATTERN RECOGNITION (2015) (achieving a 99.63\% accuracy rate).

${ }^{62}$ See Madhumita Murgia, Who's Using Your Face? The Ugly Truth About Facial Recognition, FINANCIAL TIMES, (Sept. 18, 2019), archived at https://perma.cc/AS8C-59F5 (describing "wild" photos as natural, unposed and blurred).

63 See Feature Information, SAFE SOFTWARE (Jan. 12, 2020), archived at https://perma.cc/3FFA-VS7Z (describing feature information as "information includ[ing] feature type, attributes (both user and format attributes), coordinate system, and geometry details"). See also S. Rangwala \& D. Dornfeld, Sensor Integration Using Neural Networks for Intelligent Tool Condition Monitoring, 112 
iPhones using FaceID use infrared dot projections. ${ }^{64}$ However, truthfully, the dot projections serve a much more important purpose that hints at the core of how the technology is designed-security.

Around the same time as the ground-breaking research on facial recognition was coming to fruition, researchers at University of North Carolina at Chapel Hill ${ }^{65}$ demonstrated a method of "spoofing" all existing facial recognition systems by using a 3D virtual reality model based on simple Facebook images. ${ }^{66}$ The spoofing, allowing unauthorized individuals to unlock systems relying on facial recognition technology, was incredibly successful because facial recognition at the time was solely camera based. ${ }^{67}$ In fact, even simpler spoofing worked in 2009 by merely showing a facial recognition system a still picture of $a$ face. ${ }^{68}$ In response, "liveness" checks were added to most systems, requiring movements like eye blinking or eyebrow raising during use. ${ }^{69}$ The spoofing research in 2016 blew past all liveness checks because of its virtual reality component, using a face that moves and interacts with the world in a realistic but simulated way. ${ }^{70}$ Therefore, to ensure virtual-reality

J. MANUFACTURING SCI. \& ENGINEERING 229, 229 (1990) (explaining the process of neural networks being used to integrate information from multiple sensors).

${ }^{64}$ See Face ID Security, supra note 10, at 3.

${ }^{65}$ See Yi Xu et al., Virtual U: Defeating Face Liveness Detection by Building Virtual Models from Your Public Photos, 25TH USENIX SECURITY SYMPOSIUM (2016).

${ }^{66}$ See id. at 505-06. See also Deep Dive: The Fight to Stop Biometric Spoofing, PYMNTS (Dec. 5, 2019), archived at https://perma.cc/VD8P-MBKU (defining spoofing as the process of "faking biometric identifiers to impersonate legitimate users and gain access").

${ }^{67}$ See Yi Xu et al., supra note 65, at 509 (explaining how the researchers outlined three options for overcoming the spoofing: light projection, pulse detection, and infrared illumination). Apple, at least in part, uses the first option because a pattern of illumination can be detected by the phone; the phone need only send out a pattern of light emissions and check for the corollary response. Id.; see also Bud, supra note 55 , at 5-6.

${ }^{68}$ See Yi Xu et al., supra note 65, at 497; Nguyen Minh Duc \& Bui Quang Minh, Your Face is NOT Your Password: Face Authentication Bypassing Lenovo - Asus Toshiba, BKIS (2009) (discussing an attack model that simply uses a photograph of a person's face to trick the facial recognition system). Instead of matching faces with people, these systems of the time-in reality-were more focused on merely checking if a face were present in the captured image. Id.

${ }^{69}$ See Saptarshi Chakraborty \& Dhrubajyoti Das, An Overview of Face Liveness Detection, 3 INT'L J. INFORMATION THEORY 11, 11-12 (2014).

${ }^{70}$ See Yi Xu et al., supra note 65, at 505-06. 
spoofs failed, something else besides liveness was needed. The solution, at least for Apple, was the introduction of controlled and measured illumination (i.e., the dot projections), which detect when a device or model was being used instead of a face. ${ }^{71}$

Stepping back however, consider why researchers were concerned about spoofing in the first place. What good is a key if the lock does not prevent others from entry? In other words, what are the goals of the lock — why should it be designed one way over another?

\section{B. Authentication}

The answer to these questions is authentication, a concept with roots in cryptography. ${ }^{72}$ Authentication supplies the purpose behind the key-to-lock mechanism. In this way, it is like the organic statute giving rise to systems like FaceID and TouchID. And here is authentication's statutory text - the lock should be designed to provide both identification (i.e., the presentation of something unique) and verification (i.e., corroboration of the unique identifier). ${ }^{73}$ These two elements together are found in a Request for Comments's ${ }^{74}$ definition of the "authentication process:"

Identification step: Presenting the claimed attribute value (e.g., a user identifier) to the authentication subsystem.

Verification step: Presenting or generating authentication information (e.g., a value signed with a

\footnotetext{
${ }^{71}$ See Face ID Security, supra note 10, at 3 ("To counter both digital and physical spoofs, the TrueDepth camera randomizes the sequence of 2D images and depth map captures, and projects a device-specific random pattern.").

72 Cryptography's own organic statute calls for confidentiality, integrity, and authentication. See generally JONATHAN KATZ \& YEHUDA LINDELL, INTRODUCTION TO MODERN CRYPTOGRAPHY 3-23 (CRC Press, 2d ed. 2015).

73 See STALLINGS \& BROWN, supra note 54, at 72.

${ }^{74}$ The Request for Comments (RFC) is a collection of documents, mostly managed by the Internet Engineering Task Force, regarding the protocols and technical underpinnings of the Internet. For instance, there is an RFC on Hypertext Transfer Protocol ("HTTP"), Internet Protocol ("IP"), and Transmission Control Protocol (“TCP"). See RFC 2616, archived at https://tools.ietf.org/html/rfc2616 (for HTTP); RFC 791, archived at https://tools.ietf.org/html/rfc791 (for IP); RFC 793, archived at https://tools.ietf.org/html/rfc793 (for TCP). These documents provide specific detail on the standards behind the tools of the Internet.
} 
private key) that acts as evidence to prove the binding between the attribute and that for which it is claimed. ${ }^{75}$

To understand each of these roles, consider the process of authentication (i.e., logging in) on an operating system. When a user goes to $\log$ in to a computer, the computer accepts as input a keyboardtyped password, checks this input with the previously stored password you typed when you first set up the computer, and returns a true or false depending on whether there is a match. ${ }^{76}$ Access is granted on true and denied on false. ${ }^{77}$

Similarly, FaceID takes as input the scan of a face, the scan is then compared to a scan from when the user initially setup the phone, and the system returns a true or false depending on a match. The two steps work together: (1) identification through the presentation of something unique like a face; and (2) verification through the means of a matching process.

\section{Identification: You Are Who You Say You Are}

Identification is traditionally acquired in one of three ways: ${ }^{.78}$ (1) something the user knows, like a password; (2) something the user possesses, like a token; or (3) something the user is, like a finger or face. ${ }^{79}$ The reason these identifiers work is because of exclusivity: a

75 RFC 4949 (2007), archived at https://tools.ietf.org/html/rfc4949 (providing a glossary of terminology for information system security).

${ }^{76}$ See Authentication, supra note 9 ("Entering the correct login information lets the website know (1) who you are and (2) that it is actually you accessing the website.")

77 See id. (explaining that it is important to use "uncommon, hard-to-guess passwords" because if someone knows your email address they may be able to guess your password and gain access).

${ }^{78} \mathrm{As}$ is often the case in computer science, these techniques may be combined to offer a best of both worlds approach. See, e.g., Andrew Teoh Beng Jin, David Ngo Chek Ling \& Alwyn Goh, Biohashing: Two Factor Authentication Featuring Fingerprint Data and Tokenized Random Number, 37 PATTERN RECOGNITION 2245, 2245 (2004).

79 See STALLINGS \& BROWN supra note 54, at 72.

There are four general means of authenticating a user's identity, which can be used alone or in combination: Something the individual knows: Examples includes a password, a personal identification number (PIN), or answers to a prearranged set of questions. Something the individual possesses: Examples include 
password you alone know, a token you alone have access to, and a physical feature you alone possess. Importantly, uniqueness is not the end goal here, exclusivity is - something "you alone know." 80 True enough, uniqueness is often gained with exclusivity, but this is not the gravitas of identification.

For example, no matter how unique a text-based password is, consider how simple it would be to guess and check every possible combination of characters in a three character password, otherwise known as a "brute-force" attack. ${ }^{81}$ Thus, the first method of identification-something the user knows-could leave passwordprotected content subject to access by someone without authorization. Now consider the second method-something the user possesses, such as the key to a house. Anyone in possession of the right key can gain access to the house that the key unlocks. But how do we know that the person in possession is necessarily the person with authorization to access the house? It doesn't matter how unique the key is - it matters that the key is in the exclusive possession of the authorized person. Confidence in knowing that the only person in the house is the person authorized to be there is the sine qua non of identification.

Despite the fact that uniqueness is subordinate to exclusivity, creating a password from personal knowledge may nonetheless be appropriate because passwords provide a theoretically large guessing space (typically more than three characters), making it difficult to brute-force the password. ${ }^{82}$ The same is true for something you

electronic keycards, smart cards, and physical keys. This type of authenticator is referred to as a token. Something the individual is (static biometrics): Examples include recognition by fingerprint, retina, and face. Something the individual does (dynamic biometrics): Examples include recognition by voice pattern, handwriting characteristics, and typing rhythm.

Id. Although the authors present four versions of identification, the fourth is not as common. Id.

${ }^{80}$ This ties into the Fifth Amendment because while exclusivity implies ownership (a substantive, "factual" quality), uniqueness does not.

${ }^{81}$ See sources cited supra note 26 and accompanying text (discussing the difficulty of guessing an alphanumeric password); see also What's a Brute Force Attack?, KASPERSKY (Jan. 9, 2020), archived at https://perma.cc/Q5B4-3C9Y (defining a brute-force attack as a process of deciphering a password through trial and error).

${ }^{82}$ This is why common passwords like " 12345 " completely defeat authentication's purpose. See The Importance of Strong, Secure Passwords, SECURE DATA RECOVERY (Jan. 11, 2020), archived at https://perma.cc/DU5L-34YN (setting forth 
possess, like a key, which can prevent unauthorized access so long as exclusive possession is maintained. Along the same lines, the third method of identification is also effective. Something the user is, such as a face, contains enough unique detail to acquire confidence that no one else has the same facial features, and thus access is exclusively available to the user. ${ }^{83}$

\section{Verification: Means of Corroboration}

The second part of the two-step process involves the means by which an identity is assessed. In its simplest form, verification merely requires the computer check whether two "strings" are the same. Pseudocode here is helpful to fully understand what is occurring under the hood: ${ }^{84}$

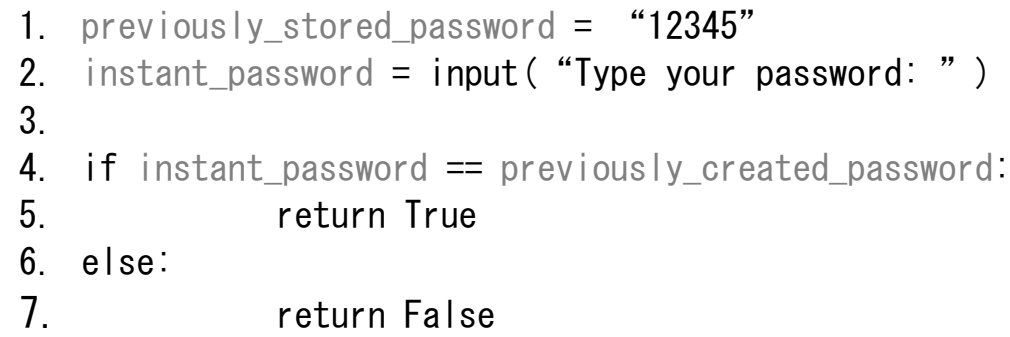

This simple process is the core of verification-using value equality "==" to see if the newly entered password (i.e. the "instant password") is the same as the previously stored password.

how passwords are similar to a lock-and-key system). If a person has the right key, then they are able to gain access. Id.

${ }^{83}$ See Gaile G. Gordon, Face Recognition Based on Depth and Curvature Features, IEEE 2 (1992) (discussing the various attributes faces impart-e.g., "nose bridge, nose base, nose ridge, eye corner cavities, convex center of the eye, eye socket boundary, boundary surrounding the nose").

${ }^{84}$ This code, based in the coding language of Python, is provided to show how simple it is to accomplish the second part of the two-step process. See Derrick Kearney, First Steps with Python, REAL PYTHON (Jan. 11, 2020), archived at https://perma.cc/C2BB-N58R. On line \#1 we store the original, previously-created password captured between parenthesis as a "string" of characters. On line \#2 we have the computer ask the user for a new, instantly-entered password. Id. The two passwords are compared for equality on line \#3, and either a successful result (line $\# 5$ ) or an unsuccessful result (line \#7) is returned. Id. 
The process is more complicated for biometrics, which is why the use of neural networks is needed. ${ }^{85}$ But if we remove a layer of abstraction, it is easy to see why neural networks are helpful- they provide feature hunting. ${ }^{86}$ To be able to recognize a face, you need to be able to tell one face apart from another. Although most faces look similar (i.e. two eyes, one nose and a mouth), there is a need to be able to distinguish faces in order to recognize them. Teasing out uniqueness, the core of the "means" of authentication, is exactly what neural networks are best for. Thus, this is why a neural network is required for facial recognition, and the same reason why Apple needed to include an extra "neural engine" processing chip (i.e. a neural network workhorse) on phones with FaceID.

In sum, for both passwords and faces, the end-result of the verification step is the same. A previously stored value is compared to a new value, resulting in either true (i.e. access granted) or false (i.e. access denied). Here, biometric authentication systems are provided with the requisite amount of uniqueness and are merely tasked with checking that uniqueness against previously stored uniqueness.

Putting it all together, facial scans, fingerprint scans, and passwords are all used for the purpose of establishing authentication. ${ }^{87}$ The primitives of this concept-identification and verification-are the bedrock on which these devices run, making them a key component in any dispute on whether a fingerprint tap, or face scan is permissibly compelled.

${ }^{85}$ See Paul Berry, Biometrics and Artificial Neural Networks: How Big Data Collection Works in Your Favor, CHICAGO POL'Y REV. (Mar. 4, 2014), archived at https://perma.cc/D8GH-T4RL (defining neural networks as security guards). Neural networks study and learn the unique traits and slight variances of a specific population, and are subsequently able to accept or deny access. Id.

${ }^{86}$ Neural networks are able to help identify facial features, which can be classified as feature hunting. See Kushan Ahmadian and Marina Gavrilova, Chaotic Neural Network for Biometric Pattern Recognition, 2012 HINDAWI PUB. CORP. 1 (2012) (introducing a more thorough study on neural networks for facial recognition technology).

87 See Robert Snelick, Large-Scale Evaluation of Multimodal Biometric Authentication Using State-of-the-Art Systems, 27 IEEE 450 (2005) (acknowledging that authentication is not a new concept, but a well-studied and highly documented one). 


\section{Authentication $==$ Truth Telling}

If unlocking a device with either a face or fingerprint scan did not impart any quantum of truth telling, then its compulsion would not offend the Fifth Amendment. An inference may be drawn from the decision in Hubbell that if the "unlock" were a neutral action having no implication of truth telling in and of itself, then its compulsion would be appropriate ${ }^{88}$ Yet, this is precisely what authentication does; compelling an individual to "place his face in front of an iPhone X" communicates a statement of fact. ${ }^{89}$

\section{A. Exclusivity Imparts a Factual Statement}

The mechanisms of "unlock" were not created in a vacuum. Just the opposite, the purpose behind these mechanismsauthentication - is a design goal that spans from decades of work. If a lock on a door did not provide security that only authorized individuals could enter, then the purpose of the lock would be lost. Likewise, if FaceID were to be easily tricked and unlocked with someone else's face, then it would be considered a failed technology.

Passwords are effective as "something you know" because at a high level they are simply something others do not know. Similarly, faces are only useful as "something you are" because no one else possesses those unique characteristics in identical form. FaceID as a feature would be considered a failure if it did not impart exclusivity, ownership, and control - the very qualities separating this act from the physical-based Fifth Amendment cases.

\section{B. Difference in Kind}

Moreover, being compelled to confirm "this is my fingerprint" is very different from confirming "this is my phone." $"$ Consider that

${ }^{88}$ See United States v. Hubbell, 530 U.S. 27, 34-35 (2000) ("The act of exhibiting such physical characteristics is not the same as a sworn communication by a witness that relates either express or implied assertions of fact or belief.").

${ }^{89}$ If the foregone conclusion were to apply, however, the result would flip.

${ }^{90}$ See e.g., sources cited supra notes 21-23 and accompanying text. The crux of the argument is that requiring a suspect to produce a set of "prints" for matching fingerprints left at the scene of the crime is the same "identification" inherent in matching a fingerprint to an iPhone. See id. This point entirely misses Riley's 
mobile devices with cloud storage options have a theoretically unlimited amount of storage potential. ${ }^{91}$ As Riley v. California ${ }^{92}$ appropriately noted, the ability to carry essentially an entire house of personal information in your pocket is not something to be taken lightly. ${ }^{93}$ The contents of this treasure trove, all of which are implicitly tied to an individual via FaceID or TouchID, are merely a glance or touch away - compelled entry into a no holds barred fishing expedition.

Further, if my fingerprint was found at the scene of the crime, ${ }^{94}$ it would not compare to the compelled presentation of all the information my phone holds (i.e. text messages, photographs, locations, etc.). ${ }^{95}$ Compelled unlock does not merely evidence a "person"-it is a binding between an incredibly detailed digital summary and an incredibly unique individual.

watershed implication - the digital world is not only different in degree, it is different in kind. See Riley v. California, 573 U.S. 373, 394 (2014).

${ }^{91}$ See Bruce Schneier, How the Supreme Court Could Keep Police From Using Your Cellphone to Spy on You, SCHNEIER ON SECURITY (Nov. 27, 2017), archived at https://perma.cc/KV8D-4J4A (claiming that the contents of your phone defining who you are is not an outlandish concept). "The cellphones we carry with us constantly are the most perfect surveillance device ever invented." Id.

92573 U.S. 373 (2014).

${ }^{93}$ See id. at 394-97 (finding that police having the ability to conduct a warrantless search of a phone, would be like finding a key in the suspects pocket and then conducting a warrantless search of a house).

${ }^{94}$ Fingerprints are not gathered in mass to reveal the location of a person for the past year, nor does a fingerprint divulge the fact that someone was "sliding into your DMs" last night). The digital world is different in kind, as Riley notes. See id.; see also Amy Mackelden, A Comprehensive Guide to Sliding Into Someone's DMs, COSMOPOLITAN (Dec. 28, 2018), archived at https://perma.cc/9X6Q-7Q4L ("Simply put, [sliding into a DM] refers to a direct message sent on social media, most often Instagram or Twitter, in which a random user or online acquaintance sends an unexpected private message.").

95 Consider the seemingly innocuous Wi-Fi toothbrush. See Andrew Guthrie Ferguson, The "Smart" Fourth Amendment, 102 CORNELl L. REV. 547, 576-77 (2017).

Most mornings I wake up and brush my teeth with a smart toothbrush that has the Wi-Fi capability to be connected with a smartphone and beyond. Data about my teeth brushing habits is generated and sent to collecting sensors and receptors. The data reveals something personal about my hygiene habits, reveals a pattern of my waking time and sleeping time, and arises from inside my person (my mouth). The data also derives from my bathroom in my home.

Id. From one simple device, information on location, wake-time, and sleep-time may derive valuable evidence to corroborate or eviscerate an alibi. Id. 


\section{Conclusion}

The binary physical-mental distinction for constitutionally compelling someone to unlock their device fails under user authentication. Due to this, odd results like permissible compulsion for fingerprints, but not passwords, occurs. Authentication imparts a truth telling - a difference in kind from obtaining a set of fingerprints or a DNA swab. The truth telling implicit in both password recall and biometric authentication is the same, ${ }^{96}$ and thus the legal result should be as well.

${ }^{96}$ Not to mention the perverse incentives of opting to use a potentially less safe method of authentication (i.e., a password) because it provides safer compulsion protection. See David Sancho, Passwords: Not Going Away Anytime Soon, TREND MiCRO (Apr. 30, 2014), archived at https://perma.cc/GU4J-93Y3. 